\title{
Albert Aubert, Du Spiritualisme et de quelques-unes de ses conséquences
}

\section{Alessandra Marangoni}

\section{(2) OpenEdition}

1 Journals

\section{Edizione digitale}

URL: http://journals.openedition.org/studifrancesi/562

DOI: 10.4000/studifrancesi.562

ISSN: 2421-5856

\section{Editore}

Rosenberg \& Sellier

\section{Edizione cartacea}

Data di pubblicazione: 1 aprile 2015

Paginazione: 183

ISSN: 0039-2944

\section{Notizia bibliografica digitale}

Alessandra Marangoni, «Albert Aubert, Du Spiritualisme et de quelques-unes de ses conséquences »,

Studi Francesi [Online], 175 (LIX | I) | 2015, online dal 01 avril 2015, consultato il 18 septembre 2020.

URL : http://journals.openedition.org/studifrancesi/562; DOI : https://doi.org/10.4000/studifrancesi. 562

Questo documento è stato generato automaticamente il 18 settembre 2020.

\section{(c)}

Studi Francesi è distribuita con Licenza Creative Commons Attribuzione - Non commerciale - Non opere derivate 4.0 Internazionale. 


\title{
Albert Aubert, Du Spiritualisme et de quelques-unes de ses conséquences
}

\author{
Alessandra Marangoni
}

\section{NOTIZIA}

ALBERT AUBERT, Du Spiritualisme et de quelques-unes de ses conséquences, texte établi, avec introduction et notes par Barbara WRIGHT, London, Modern Humanities Research Association, vol. 44, 2014, pp. XXXII-48.

1 Trattasi della prima edizione di un manoscritto del 1840, ritrovato tra le carte di Eugène Fromentin (quest'ultimo e l'autore del saggio, Albert Aubert, si erano conosciuti all'École Normale Supérieure). La curatrice vi rinviene l'impronta di Quinet, tracce di Michelet e dell'eclettismo di Victor Cousin.

2 Anche se Albert Aubert fu prevalentemente un giornalista, la pubblicazione di questo suo saggio in due parti ha il merito di portare alla luce una testimonianza inedita sulla riflessione filosofico-religiosa durante la Monarchia di Luglio. Il clima imperante è quello dello spiritualismo di Maine du Biran. Ma sono soprattutto messe in evidenza le conseguenze negative dello spiritualismo: in filosofia un dualismo accentuato tra anima e corpo, in campo morale un eccesso di abnegazione e di ascesi, nelle arti un rigurgito di grandi sentimenti o di sentimentalismo tout court; in poesia, in particolare, una degenerazione della forma (così come il corpo, nel sentire spiritualista, si dissolve a profitto dell'anima).

3 Parimenti rigettato dal materialismo del XVIII secolo, l'Autore sarebbe così propenso a una sorta di spiritualismo laico (secondo formula di Bénichou) fondato su valori essenzialmente morali, orientati al progresso della società, senza però che questa schiacci l'individuo. 